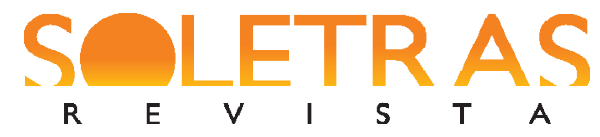

\title{
Entrevista
}

\section{Laboratório de Linguagem e Processos Cognitivos (LabLing)}

\author{
Mailce Borges Mota ${ }^{1}$
}

Universidade Federal de Santa Catarina

\section{Entrevista concedida aos professores Kátia Abreu e Eduardo Kenedy}

Soletras: Quando o seu LAB foi fundado? Qual foi sua experiência em LABs de Psicolinguística anterior à fundação do LAB que coordena?

O Laboratório da Linguagem e Processos Cognitivos (LabLing) foi criado em 2011. O LabLing é vinculado ao Programa de Pós-Graduação em Linguística e ao Programa de PósGraduação em Inglês, ambos na Universidade Federal de Santa Catarina. Anteriormente à criação do LabLing, realizei um pós-doutorado no Brainand Language Lab, na Georgetown University (Washington, DC), sob a supervisão de Michael Ullman (2008-2009).

Soletras: Quais os principais temas de pesquisa que seu LAB vem contemplando ao longo dos anos?

O objetivo principal do LabLing é investigar a relação entre o processamento da linguagem e outros sistemas e mecanismos cognitivos e neurocognitivos, sobretudo os de memória e os de atenção. Nossos estudos abordam fenômenos morfossintáticos, lexicais ou sintáticos, em L1 ou L2, e procuram elucidar de que forma esses fenômenos interagem com a memória de trabalho, a memória declarativa e a memória procedural bem como com mecanismos atencionais, como o controle executivo. Procuramos investigar, também, as bases neurais dessa interação. Nossa agenda de pesquisa está organizada a partir de família de estudos. Nos últimos anos, por exemplo, temos nos interessado em estudar o processamento da morfologia flexional (nominal e verbal) para testar as hipóteses de modelos unitários e modelos duais em falantes de português brasileiro (como L1 e L2) e inglês (como L1 e L2), especialmente as hipóteses relacionadas ao papel de sistemas de memória. Em outro grupo de estudos, investigamos as influências translinguísticas no acesso lexical e no processamento

\footnotetext{
${ }^{1}$ Professora Associada IV do Departamento de Língua e Literatura Estrangeiras da UFSC. É também membro do Programa de Pós-Graduação em Inglês e do Programa de Pós-Graduação em Linguística, na mesma instituição. mailcemota54@gmail.com
} 
sintático. Um terceiro grupo de estudos investiga o processamento sintático em L1 e L2 a partir do paradigma de priming sintático e à luz de modelos neurocognitivos de processamento da linguagem que atribuem papel relevante a sistemas de memória e ao controle executivo, como o modelo Memória, Unificação e Controle, de Peter Hagoort. Por fim, um quarto grupo de estudos investiga o papel da memória de trabalho na aprendizagem de habilidades linguísticas e no processamento. De modo geral, nossos estudos incluem populações diversas ï como adultos jovens saudáveis e crianças com desenvolvimento típico, disléxicos, adultos longevos e adultos analfabetos $\ddot{i}$ e procuram contribuir com implicações pedagógicas para a educação escolar brasileira.

Soletras: Quais as principais técnicas experimentais que vêm sendo empregadas nas pesquisas de seu Lab nos últimos anos?

Nossos estudos empregam técnicas comportamentais online tradicionais, em que somente um bom computador é necessário para o registro de dados, ou mais de ponta, como o rastreamento ocular. Uma de nossas prioridades é nos aprimorarmos no uso da eletroencefalografia para o registro de potenciais relacionados a eventos. Estamos iniciando, também, estudos que utilizam técnicas hemodinâmicas, como a ressonância magnética funcional.

Soletras: Você poderia fazer uma estimativa do total de pesquisas de mestrado e doutorado que foram conduzidas no Lab?

Diretamente vinculadas ao LabLing, ou seja, após sua criação, em 2011, foram conduzidas 5 teses de doutorado e 11 dissertações de mestrado.

Soletras: O Lab integra alguma rede de cooperação? Poderia citar outros Labs parceiros?

Os estudos atualmente em andamento são todos financiados por agências de pesquisa brasileiras ou estrangeiras e estão vinculados a projetos desenvolvidos com diversos colaboradores em diferentes laboratórios e instituições. Atualmente temos projetos em conjunto com o Max Planck Institute for Psycholinguistics, por meio do Programa CAPES/NUFFIC, em colaboração com Peter Hagoort; com a University of Bristol/UK, em colaboração com Markus Damian (Newton Fund/British Academy); University of Birmingham/UK, em colaboração com Katrien Segaert e Ali Mazaheri (Newton Fund/British 
Academy); com o Instituto do Cérebro da PUCRS e Instituto do Cérebro da UFRN, no âmbito do Projeto ACERTA (Programa Observatório da Educação/CAPES), um projeto em rede com Augusto Buchweitz e Sidarta Ribeiro; e com o Núcleo de Estudos em Aquisição da Linguagem e Psicolinguística da UFJF, em colaboração com Cristina Name (FAPEMIG/CNPq). Fazemos parte também da Rede Nacional de Ciência para a Educação.

Soletras: Além de trabalhos teóricos de interesse para a área da Psicolinguística, seu Lab desenvolve também pesquisas de interface com a área da Saúde elou da Educação? Se sim, quais?

Desde muito antes da criação do LabLing, as dissertações de mestrado e doutorado que oriento têm como um de seus princípios, além de procurar pelo aperfeiçoamento do rigor metodológico e da análise dos dados, oferecer contribuições para a educação escolar, tanto no que diz respeito ao ensino quanto à aprendizagem. No momento, todos os projetos em andamento que recebem aporte financeiro de agências de fomento, envolvem professores e alunos da educação básica e têm como objetivo investigar o processamento da linguagem em populações que estão em fase de aprendizagem escolar.

Soletras: Deixe uma palavra de seu Lab para os leitores alunos de graduação interessados em ingressar na área da psicolinguística experimental.

A psicolinguística experimental é uma área fascinante que se desenvolve rapidamente e que atrai cada vez mais pesquisadores. Tem a seu dispor um bom conjunto de técnicas que permitem o estudo de processos cognitivos e neurocognitivos com precisão. É um campo rico que nos possibilita estudar a aquisição e o processamento da linguagem tanto para o desenvolvimento de teorias quanto para a aplicação em contextos diversos, como a saúde e a educação. Entretanto, por demandar conhecimento em outras áreas para além da Linguística (por exemplo, conhecimento de linguagens de programação, de testes estatísticos, de diversos tipos de software e hardware), a psicolinguística experimental apresenta desafios que, por sua vez, exigem tempo para serem vencidos. Assim, quanto mais cedo o aluno de graduação puder se envolver com o planejamento e condução de experimentos, mais fácil será se apropriar do conhecimento paralelo que é necessário para a execução de um bom estudo de natureza experimental sobre os processos cognitivos e neurocognitivos que viabilizam a aquisição e o processamento da linguagem. O LabLing tem interesse em estudar esses 
processos no que diz respeito à relação entre linguagem, sistemas de memória e mecanismos atencionais. Estamos sempre abertos a novas colaborações.

Entrevista realizada 23 de junho de 2017. 